\title{
EL DERECHO DE LOS "PUEBLOS SIN DERECHO": ELEMENTOS PARA DEBATIR UNA RECONSTRUCCIÓN DEL CAMPO JURÍDICO DE LOS JUECES DE TENENCIA EN LAS COMUNIDADES PURÉPECHAS DE MICHOACÁN, MÉXICO
}

\author{
THE LAW OF THE "PEOPLES WITH NO LAW": \\ ELEMENTS FOR A DEBATE ON THE RECONSTRUCTION OF THE \\ LEGAL FIELD OF THE PURHEPECHA COMMUNITIES JUDGES \\ OF TENENCIA IN MICHOACÁN, MÉXICO
}

Orlando Aragón Andrade*

\begin{abstract}
RESUMEN: En este trabajo realizo, a través de la experiencia del estudio de las justicias indígenas aplicadas por los jueces de tenencia en Michoacán (México), una crítica a la forma de hacer la historia de los otros derechos distintos al estatal. La crítica la enfilo en una doble dirección; por un lado, la dirijo a mostrar el papel que ha jugado la historia del derecho tradicional en la formación de la relación de hegemonía entre las justicias indígenas y el derecho estatal, y por el otro, la enfoco en cuestionar algunos principios metodológicos de esta forma tradicional de hacer historia del derecho, particularmente en el uso de sus fuentes de investigación.
\end{abstract}

PAlABRAS CLAVE: Historia del derecho. Justicias indígenas. Pluralismo jurídico.

ABSTRACT: Throughout the study of the indigenous justices applied by tenencia judges in Michoacán (México), this work endeavors a critique of the way in which the history of non-state law is constructed. The critique is headed in two different directions; on one side, I pretend to show traditional history's role in shaping the hegemonic relation between indigenous justices and state law, and on the other side, I focus on questioning some of the methodological principles of this traditional way of doing history of law, particularly in the use of their research sources.

KEYWORDS: History of law. Indigenous justices. Legal pluralism.

* Candidato a doctor en Ciencias Antropológicas. Profesor de la Facultad de Derecho y Ciencias Sociales de la Universidad Michoacana de San Nicolás de Hidalgo, México. PhD Candidate in Anthropological Sciences. Professor at the Law and Social Sciences Faculty, Universidad Michoacana de San Nicolás de Hidalgo, México. 
Quiero iniciar esta intervención retomando las palabras que dirige Próspero a Calibán en la célebre obra de William Shakespeare "La tempestad":

Esclavo aborrecido, incapaz de tomar huella alguna de bondad, pero sí capaz de todo mal. Tuve compasión de ti, me tomé el trabajo de enseñarte a hablar, te enseñaba a cada momento una cosa u otra; cuando tú, salvaje, no conocías tus propios pensamientos y balbucías confusamente como lo hace un bruto, yo di a tus ideas las palabras necesarias para hacerse conocer. Pero a despecho de lo que pude enseñarte, nada bueno ha llegado a unirse a tu innoble naturaleza. Con justicia, pues, fuiste confinado a esa peña, tú que habías merecido más que una cárcel (SHAKESPEARE, 2009: 196).

Estas líneas ilustran paradigmáticamente, desde mi punto de vista, la construcción de las relaciones de alteridad, que precisamente deseo discutir en este trabajo, particularmente la de la historia de los derechos o mejor dicho de las justicias de las comunidades purépechas de Michoacán.

De entrada puede que suene desproporcionada la cita inicial para analizar cualquier elemento cultural, entre ellos las justicias de los pueblos indígenas, sobre todo cuando la ideología dominante en nuestros días, en México y a nivel global, ha tomado la forma del multiculturalismo y de la tolerancia.

Las justicias de las comunidades y pueblos indígenas, podrán pensar, están ya reconocidas en el artículo $2^{\circ}$ de la constitución federal de México $^{1}$ y la existencia de dicho reconocimiento no pareciera corresponder con la duresa de la relación expresada en las palabras que Próspero dirige a Calibán. No obstante, este reconocimiento, desde mi punto de vista, es la misma prueba de la vigencia de esta relación de alteridad en la idea más difundida sobre las justicias de los pueblos indígenas o ¿acaso no únicamente se permite la aplicación de éstas siempre y cuando que no contravengan al propio derecho estatal? ¿en realidad se está proponiendo una relación de verdadero pluralismo jurídico y de multiculturalismo, si de cualquier manera aquello que no está explícitamente prohibido por el derecho estatal está permitido? cuánto se ha avanzado, verdaderamente, en esta convivencia en relación a la época colonial cuando las leyes de indias disponían que:

Ordenamos y mandamos, que las leyes y buenas coftumbres, que antiguamente tenian los Indios para fu buen gobierno y policia, y fus vfos y coftumbres obfervadas y guardadas defpues que fon Chriftianos, y que no fe encuentran con nuelfta Sagrada Religión, ni con leyes de efte libro, y las que han hecho y ordenado de nuevo fe guarden y executen [...] (LÓPEZ, 2000: 86).

1 En México en el año de 2001 se reconoció a las justicias o sistemas normativos de los pueblos indígenas en la constitución federal como una consecuencia del movimiento zapatista. No obstante, la calidad del reconocimiento es polémica; para algunos autores se trata de un engaño y un falso reconocimiento, para otros en cambio se trata de un gran avance en la conformación de un Estado plurinacional. Véase entre otros: (GONZÁLEZ, 2002; CABEDO, 2004 y ARAGÓN, 2007). 
Ahora bien ¿la historia del derecho, en México, como disciplina social ha hecho o dejado de hacer algo para contribuir a este status legal y sobre todo a la formación del imaginario sobre las justicias de las comunidades indígenas como algo atrasado? A mí me parece que se puede responder que afirmativamente, obviamente no tanto en el aspecto legal, pero sí en el del imaginario sobre las justicias indígenas que termina alimentando y legitimando el aspecto legal. No obstante, este último aspecto tiene una consecuencia doble no sólo "desfigura" a las justicias indígenas también contribuye a defender y promover la imagen hegemónica del propio derecho estatal.

Sobre estos últimos dos puntos son sobre los que me quiero concentrar en adelante con la finalidad de formular una doble crítica, tanto metodológica como política, a la historia del derecho que voy a llamar "tradicional". Este objetivo pretendo alcanzarlo basándome en el ejemplo de la historia reciente de los juzgados de tenencia en las comunidades purépechas de Michoacán, México.

\section{II}

Antes de iniciar la crítica metodológica creo necesario explicitar que el problema con las aproximaciones históricas tradicionales a las justicias indígenas es que se basan en una relación de alteridad, que al tiempo que desvirtúan al "otro", en este caso al "otro derecho" o a las "otras justicias", encubren y legitiman una posición de poder. ¿Cómo se produce este proceso de alteridad? En términos muy generales se puede decir que a partir de la creación de categorías dicotómicas que son dotadas de contenidos opuestos. En este sentido la vieja reflexión del filosofo renacentista Michel de Montaigne en su ensayo clásico sobre "De los caníbales" es elocuente:

lo que ocurre [señala Montaigne] es que cada cual llama barbarie a lo que es ajeno a sus costumbres. Como no tenemos otro punto de mira para distinguir la verdad y la razón que el ejemplo e idea de las opiniones y usos del país en que vivimos, a nuestro dictamen en él tienen su asiento la perfecta religión, el gobierno más cumplido, el más irreprochable uso de todas las cosas. ${ }^{2}$

Esta racionalidad moderna-occidental ha creado una serie de dualidades como las de civilizado/bárbaro, alta cultura/baja cultura, moderno/tradicional, indígena/mestizo, derecho estatal/"usos y costumbres", que siguen el mismo impulso de extrapolación y que tienen también el doble efecto de excluir y de legitimar. ${ }^{3}$

Para el tema que me interesa las últimas tres dicotomías forman una constelación que explica la relación hegemonizada entre el derecho estatal y las justicias indígenas.

2 MONTAIGNE, Michel de. De los caníbales. Disponible en: < http://bibliotecaignoria.blogspot. com/2010/02/michel-de-montaigne-de-los-canibales.html > . Acceso en: 17/11/2011.

3 Véase: (SANTOS, 2007). 
De tal forma que en la dicotomía "moderno/ tradicional", el primer término es identificado con características como científico, avanzado, evolucionado, racional, etcétera; frente a lo "tradicional" que es concebido como anclado al tiempo, inmutable, acientífico, irracional, atrasado, entre otros. Su actualización y "mexicanización” queda constituida por la segunda dicotomía "mestizo/indígena”, en la cual la primera categoría, apoyada en la ideología nacionalista posrevolucionaria, nuevamente es connotada de progreso, cultura nacional, nacionalismo, entre otros; mientras que su opuesta es identificada con atraso, cultura folclórica, conservadurismo pre nacionalista, etcétera. Finalmente la tercera dicotomía se establece entre "derecho estatal / justicias indígenas"; así pues mientras el primero está a la vanguardia del conocimiento científico, tiene potencial de globalización, responde a las dinámicas sociales contemporáneas; a las justicias indígenas se les identifica con lo irracional, como prácticas destinadas a permanecer en pequeñas áreas, basadas y ancladas en prácticas pasadas, entre otras características.

El resultado de esta constelación de dicotomías es precisamente el que da sustento a las nociones que ha predominado tanto del derecho estatal como de las justicias indígenas y que me parece sintetizan los elementos que he descrito. Entonces habría que preguntarnos si en realidad la cita con que abrí este trabajo es exagerada ¿no acaso el actual estatus legal de las justicias indígenas, su tutelaje por el derecho estatal, está sustentado en una idea de que no se puede esperar nada bueno de ellas? ¿no acaso, en la mejor de las situaciones, se les consideran como manifestaciones de lo jurídico condenadas a los "márgenes del Estado" o como lo dice el mismo Próspero "a estar confinadas a una peña"?

Ahora bien, con estos planteamientos no pretendo invertir las categorías y caer en un romanticismo esencialista respecto a las justicias indígenas en el cual éstas aparezcan como reductos de pureza, equilibrio, orden inmanente, obediencia voluntaria frente a la corrupción, violencia, ineficacia del derecho estatal; no... nada más lejano a esto. Asumir una defensa de las justicias indígenas de este tipo lejos de ayudar a revertir el imaginario sobre su atraso alimenta la potencia de la lógica dicotómica que las excluye.

Una postura verdaderamente crítica no puede quedarse en un acto de nostalgia premoderna o en una moda new age que a la larga seguiría nutriendo y reforzando la exclusión; por el contrario lo que argumentaré es que no hay tal división entre lo moderno y lo tradicional, entre el derecho estatal y las justicias indígenas; sino que forman parte de la misma temporalidad y que son interdependientes uno del otro. ${ }^{4}$ Este procedimiento permite hacer "contemporáneas" a las justicias indígenas, así como "civilizarlas", pero al tiempo exponer la hegemonía del derecho estatal y mostrar sus múltiples caras que

4 Este argumento ha sido desarrollado con mayor amplitud por la profesora Paola Meneses analizado las particularidades del caso del derecho consuetudinario en Mozambique. Véase: (MENESES, 2004). 
no se reducen a la caricatura monolítica de la ley y que buena parte de la literatura histórico jurídica se ha encargado de difundir y legitimar.

Lo que habría que hacer antes que nada, siguiendo a las teorías poscoloniales, es desechar esta estructura del pensamiento moderno occidental que Boaventura de Sousa Santos ha denominado el pensamiento abismal (SANTOS, 2007). Pero ¿Cómo se puede abandonar esta lógica dicotómica/abismal del pensamiento moderno, sin quedarse en la superficialidad del romanticismo? ¿Cómo se debe, entonces, considerar a las justicias indígenas? ¿Cómo entender un derecho que está íntimamente identificado como tradicional?

Me parece hay que empezar por aceptar el carácter híbrido y la naturaleza política ambigua de las justicias indígenas. En este sentido tendríamos que recordar la advertencia que Eric Hobsbawm hace en su célebre trabajo sobre "La invensión de la tradición" respecto al papel decisivo que el Estado juega en este proceso de creación de lo tradicional (HOBSBAWM, 2002).

En ese mismo sentido, Carlos Paredes ha señalado con gran acierto que las instituciones indígenas de Michoacán son en realidad producto, por un lado, de la imposición colonial, y por el otro de la adaptación y recreación de éstas por parte de los pueblos indígenas asentados en su territorio (PAREDES, 2003: 131-132). Eduardo Zarate en una dirección similar también ha sostenido que el gobierno local de las comunidades indígenas:

constituye el vínculo político esencial que permite a la comunidad étnica ser parte de entidades más complejas (el Estado) y a la vez que mantener intereses propios.[...] Por un lado, un gobierno interno, cuya finalidad es dirimir los conflictos entre unidades operantes de la comunidad de acuerdo al derecho y a la costumbre local, evitando el desplazamiento de conflictos a la sociedad extracomunal; y, por el otro, un gobierno que se encarga de vincular a la comunidad con el exterior [...], pero sobre todo de regular la intervención del sistema externo en la vida interna de la comunidad (ZÁRATE, 2001: 153).

Estas ideas son perfectamente aplicables para entender a las justicias indígenas no como un reducto de prácticas legales atrasadas y desvinculadas del derecho estatal y de su temporalidad, sino como un espacio intermedio constantemente negociado y disputado entre las comunidades indígenas y el Estado $;^{5}$ que por una parte, les ha permitido a los indígenas administrar cierto grado de autonomía interna, pero al mismo tiempo ha sido de capital importancia en la formación del Estado en esas regiones. ${ }^{6}$

5 Desde mi punto de vista las justicias indígenas comparten el carácter político de las justicias populares, que es indefinido de manera apriorística y que es constantemente disputado entre la comunidad y el Estado. Véase: (MERRY, 2004).

6 Roberto Varela ha explicado muy bien las dinámicas de las autoridades locales en México en relación con las autoridades centrales. Véase: (VARELA, 1984: 55-58). 
Así pues, el derecho estatal y las justicias indígenas no son polos opuestos con características encontradas, sino que forman parte de un mismo sistema que dista mucho de las representaciones que tradicionalmente se han construido desde la historia del derecho.

\section{III}

Sé que a esta altura del trabajo todavía no he dejado bien en claro el vínculo de esta discusión teórica con la historia del derecho como disciplina social, pero ahora me ocuparé de esta cuestión. ¿Cómo ha intervenido la historia del derecho en la consolidación del imaginario atrás combatido?

Yo diría que a partir del mismo esquema dicotómico/abismal que he descrito. Hay que recordar que en la historia del derecho no hay una dimensión plural del fenómeno jurídico a diferencia, por ejemplo, de la sociología y la antropología del derecho. ${ }^{7}$ Me parece que en la historia tradicional del derecho opera subterráneamente una distinción formalista de la dogmatica que a su vez se funda en la racionalidad dicotómica jurídica que diferencia al derecho estatal de las otras expresiones del fenómeno jurídico que son consideradas como irrelevantes y que ni siquiera merecen el status de derecho; sino de simples "usos y costumbres", "derecho consuetudinario", "derecho primitivo", "convencionalismos sociales", pero en ningún caso derecho.

Por eso cuando en nuestros días se habla de la historia del derecho, se hace de una manera verdaderamente estricta, en realidad a lo que se refiere es a la historia de un derecho: el Estatal. Esta advertencia la ha realizado de manera acertada el historiador y antropólogo del derecho Norbert Rouland quien nos recuerda a los historiadores del derecho que "el derecho, como multiplicidad de experiencias de lo jurídico, tiene historias" en plural y no una sola (ROULAND, 2003: 31-93).

Ustedes podrán pensar que tal vez nuevamente estoy exagerando, ya que este vacio puede ser ocasionado por un trágico descuido o desatención y no por un mecanismo de exclusión; mi hipótesis, en cambio, va en otro sentido; la marcada ausencia de esta dimensión plural en la historia del derecho es nuevamente producto de este pensamiento abismal. Permítanme abundar más en este punto.

Me parece que aquí encontramos otro elemento propio del pensamiento dicotómico; el derecho estatal además de las características ya señaladas es concebido como escrito, en oposición a las justicas indígenas que supuestamente son orales y por lo tanto "no derechos", sino "usos y costumbres", "derecho consuetudinario", "prácticas inmemoriales", etcétera.

7 Tal vez la excepción a la regla más conocida es la obra del profesor italiano Paolo Grossi que sí retoma en su análisis la idea de pluralismo jurídico. Véase entre otros: (GROSSI, 1996 y GROSSI, 2003) 
En ese sentido cobra una dimensión importante el hecho de que las fuentes privilegiadas por excelencia por la historia del derecho sean escritas, puesto que responden a la lógica de la historia del derecho estatal, pero al mismo tiempo nos permite entender, en parte, la exclusión de las "otras historias del fenómeno jurídico" como "la historia de las justicias indígenas." Precisamente este es el punto del trabajo clásico de Eric Wolf "Europa y la gente sin historia" y su crítica a las representaciones hechas tanto de la historia Europea como de las sociedades "ágrafas" (WOLF, 2006).

Por supuesto, los historiadores que tengan conocimiento o trabajo en derecho indiano o en algunas otras áreas de estudios de la subdisciplina podrán alegar que sí hay estudios sobre cómo las comunidades indígenas impartían justicia a partir de los testimonios escritos registrados por las instituciones eclesiásticas o estatales; sin embargo, y es aquí donde está nuevamente el punto de la discusión ¿cuál es el precio que se paga en esas investigaciones? ¿Acaso no las fuentes principales en que se sustentan estos trabajos caen dentro del marco del problema de la alteridad o de la representación “distorsionada" del "otro"? ¿no estamos otra vez encarnando a Próspero cuando señalaba en la cita inicial "yo di a tus ideas las palabras necesarias para hacerse conocer"? es decir, en pocas palabras ¿no al usar como materia prima a los testimonios estatales y eclesiásticos para reconstruir pasajes de la administración de justicia en las comunidades estamos ante una representación de las justicias indígenas hechas desde un poder hegemónico? y si me permiten llevar más allá la pregunta ¿no es lógico que estas fuentes sean autoreferenciales en cuanto al discurso que el derecho estatal y eclesiástico da de sí mismo y sobre las justicias indígenas?

Para muchos colegas tal vez este sea el precio que necesariamente se tiene pagar para conocer algo de estas "prácticas jurídicas". Desde mi punto de vista esta posición sólo es parcialmente cierta, creo que es posible conocer la historia de las justicias indígenas de otra manera. En adelante quiero ejemplificar mi afirmación mostrando el caso particular de los jueces de tenencia de las comunidades purépechas en Michoacán, México.

\section{IV}

Los juzgados de tenencia eran una figura perteneciente a la estructura tribunal estatal de la provincia de Michoacán que estuvo vigente hasta el año del 2007 y que sus orígenes pueden ser rastreados hasta la época colonial. Si bien estos aparatos judiciales nunca fueron creados explícitamente para las comunidades indígenas de Michoacán, en éstas, particularmente en las purépechas, ocupaban y ocupan un lugar muy importante en la impartición de su justicia a tal grado que las comunidades las consideran como parte de sus autoridades tradicionales. 
Los juzgados de tenencia eran también el peldaño más bajo de la estructura judicial del tribunal; su justicia era impartida por legos (generalmente campesinos de las tenencias que son localidades de pequeña extensión geográfica) no registraban expedientes por escrito, por tal motivo poco se sabe de esta justicia. No obstante, existen, como ocurre en prácticamente todos los periodos históricos, fuentes documentales del derecho estatal que sí proporcionan algunos pocos elementos para "conocer" su funcionamiento, aunque como lo argumenté se encuentran dentro de las coordenadas de la problemática de alteridad planteada.

Por ejemplo, la última ley orgánica tribunal que los contempló disponía que estos jueces serían elegidos por el pleno de los magistrados, que durarían en su en cargo un año, que su competencia se restringiría al campo civil y su cuantía no pasaría de los 1000 pesos. Por supuesto ustedes podrían decir la ley es apenas una de las fuentes de la historia del derecho, en efecto, el problema es que fuera de la ley se conservan muy pocos otros testimonios escritos sobre estos juzgados.

Además de la ley sólo dos fuentes escritas nos dan cierta información sobre estos juzgados y son (I) las actas del pleno de magistrados donde se realizaban los nombramientos oficiales de los jueces y (II) algunos pocos informes escritos por funcionarios judiciales que por motivos excepcionales realizaban vistas a los juzgados de tenencia.

El estudio de estas dos fuentes revela que contrario a lo que la ley establecía, los jueces de tenencia eran electos por la propia comunidad y el pleno de magistrados únicamente ratificaba los nombramientos; también dan cuenta estos documentos de que el tribunal le tomaba parecer a las autoridades municipales sobre los nombramientos de estos jueces; no obstante, más allá de esta información poco más nos permiten conocer sobre la justicia impartida por los jueces de tenencia en la comunidades purépechas. En algunas otras fuentes como los viejos informes anuales de los magistrados presidentes del tribunal se encuentran testimonios marginales como el siguiente:

Lo dicho por los jueces [de tenencia] de Nicolás Obispo y de Caltzontzin, también es característico de la justicia en los pequeños poblados y hace recordar formas primitivas de penar. El primero comunica literalmente: "se han arreglado demandas entre los vecinos, pero no se les cobra, se les sanciona con multa de que traigan se una silla de tule cuando hay arreglo y cuando no lo hay se mandan a donde corresponde". El segundo, aunque no tienen competencia penal, expresa textualmente: "El suscrito ha intervenido en 10 casos por lesiones, o sea golpes contusos. El C. Jefe de Tenencia del lugar hizo las consignaciones, sin llegar a formar expediente, ya que a petición de los propios ofendidos y hechores, llegaron a un arreglo conciliatorio al cubrirse completamente la reparación del daño. ${ }^{8}$

8 PLENO EXTRAORDINARIO DEL DÍA 13 DE SEPTIEMBRE DE 1978, Caja Núm. 585, Sección de documentos administrativos, Archivo Judicial del Supremo Tribunal de Justicia del Estado. 
Un buen ejemplo de la información y el sentido que nos dan los testimonios recabados en las visitas realizadas a los jueces de tenencia en comunidades purépechas es el siguiente:

En la Tenencia de Tarecuato, Municipio de Santiago Tangamandapio, Michocán, siendo las 15.30 quince treinta horas del día 20 veinte de abril de 1988 mil novecientos ochenta y ocho, el suscrito Juez Primero de Primera Instancia en materia Civil de este Distrito Judicial, en cumplimiento al acuerdo del H. Pleno del Supremo Tribunal de Justicia del Estado del día 7 siete del presente mes se procedió a realizar la investigación ordenada en dicho acuerdo, para cuyo efecto se interrogó a diversas personas vecinas del lugar quienes manifestaron desconocer todo lo relativo al conflicto presentado con motivo por la designación de Jueces de Tenencia, considerando pertinente hacer notar la dificultad que se presenta para hacerse entender a los vecinos del lugar. Por las razones expuestas se procede a entrevistarse con el ciudadano Jefe de Tenencia señor Roberto Amezcua Mateo, quien indicó que el fín [sic.] que se persigue con la designación de los nuevos Jefes de Tenencia es el que se trabajen en conjunto todas las Autoridades y no únicamente coperen [sic.] en la celebración de fiestas religiosas. ${ }^{9}$

Es innegable que la combinación de estas fuentes escritas ya pueden aportarnos más elementos para conocer algo del "derecho de los pueblos sin derecho"; sin embargo, también lo es que la información es aun escasa e incoherente entre sí, pero sobretodo cruzada por la relación dicotómica planteada en este trabajo. ¿cuál puede ser, entonces, la alternativa para superar esta dificultad? ¿cuál es el camino para liberar a la historia del derecho de esta racionalidad abismal? Mi respuesta es sencilla repensar y reequilibrar las fuentes de información con que trabajamos.

Un derecho que no es escrito, implica antes que nada investigarlo en fuentes que privilegien ese carácter. Por supuesto, no se trata de la absurda operación de desechar las fuentes escritas, sino a partir de las fuentes no escritas, que pueden ser de diversa índole reconstruir un argumento que pueda ser contrastado con la información que nos dan las fuentes escritas.

Para el caso con que he ejemplificado esta contribución, logré superar varios de los problemas aquí planteados a partir de entrevistas a jueces y exjueces de tenencia (que a pesar de que no existen ya en la ley en la práctica todavía operan en muchas las comunidades purépechas) en combinación con las fuentes escritas y testimonios de exfuncionarios judiciales y de esta manera construir una historia reciente de los últimos 30 años de su funcionamiento.

A partir de esta información pude saber, por ejemplo, que los jueces de tenencia eran nombrados por las propias comunidades, que en la práctica había cuando menos tres sistemas elección distintos, que la duración de los jueces en su cargo era altamente

9 DOCUMENTACIÓN RELATIVA A LOS ACUERDOS TOMADOS POR EL PLENO DEL SUPREMO TRIBUNAL DE JUSTICIA DEL ESTADO EN LA SESIÓN ORDINARIA CELEBRADA EL DÍA 4 DE MAYO DE 1988, Caja Núm. 753, Sección de documentos administrativos, Archivo Judicial del Supremo Tribunal de de Justicia del Estado. 
variable en algunos un año, otros de dos, otros de tres e incluso en comunidades donde el juez duraba hasta que muriera. Que en cada una de las 10 comunidades donde trabajé con sus jueces y otras autoridades las competencias judiciales de los jueces variaban a veces radicalmente y que las compartía con otras autoridades híbridas que en teoría no tendrían atribuciones judiciales como el jefe de tenencia y el comisariado de bienes comunales; que en muchas comunidades los jueces conocen asuntos penales relativamente importantes a pesar de lo que disponía la ley en este aspecto, que en todos los casos la cuantía establecida para materia civil era ampliamente rebasada, que hay comunidades donde los jueces nombrados por el tribunal únicamente tenían funciones religiosas y no judiciales, y en otras tantas los jueces desempeñaban ambas judiciales y religiosas; que cuando no podían resolver algún conflicto lejos de enviarlo a la instancia judicial inmediata como los juzgados municipales o los de primera instancia eran enviados a autoridades del poder ejecutivo como el síndico municipal y los Ministerios Públicos, entre otras.

Evidentemente no pretendo decir que la utilidad de re-imaginar la investigación histórico jurídica sea útil sólo porque nos permite construir un conocimiento más verdadero; no. Me parece más bien que los resultados de esta forma de construir "la historia de las justicias indígenas" nos permiten hacernos preguntas para el pasado y para el presente como ¿en realidad la justicias indígenas son una especie de reducto primitivo que ha sobrevivido hasta nuestro tiempo posmoderno o es un elemento constitutivo de nuestros días que forma parte de la misma temporalidad que el derecho estatal? ¿en realidad el derecho estatal es ese bloque monolítico que la ley y gran parte de la literatura histórico jurídica nos ha enseñado? A partir de la experiencia de los jueces de tenencia ¿se puede sostener que el derecho estatal está separado de la religión, al menos en ese nivel? 0 ¿que en el derecho estatal opera una clara división de poderes en cuanto a las funciones judiciales?

Una historia crítica que se aproxime de forma distinta a la condicionada por la relación de alteridad, empieza por un distanciamiento de las fuentes tradicionales de la historia del derecho; pero ésta no se limita a un afán positivista de mejores o verdaderos conocimientos, a los cueles no se renuncia obviamente, sino que esta operación busca centralmente pensar de forma distinta las historias del fenómeno jurídico, y en este caso en particular el pasado y el presente del derecho estatal y de las justicias indígenas.

\section{REFERENCIAS BIBLIOGRÁFICAS}

ARAGÓN ANDRADE, Orlando, 2007, Los sistemas jurídicos indígenas frente al derecho estatal en México. Una defensa del pluralismo jurídico. En: Boletín mexicano de derecho comparado. México D.F., n. 118.

CABEDO MALLOL, Vicente, 2004, De la intolerancia al reconocimiento del derecho indígena. En: Política y cultura, México D.F., n. 21. 
GONZÁLEZ GALVÁN, Jorge Alberto, 2002, La validez del derecho indígena en el derecho nacional. En: CARBONELL, Miguel y PÉREZ PORTILLA, Karla (Coords.). Comentarios a la reforma constitucional en materia indígena. México: UNAM.

GROSSI, Paolo, 1996, El ordenamiento jurídico medieval. Madrid: Marcial Pons.

GROSSI, Paolo, 2003, Mitología jurídica de la modernidad. Madrid, Trotta.

HOBSBAWM, Eric, 2002, Introducción: La invención de la tradición. En: HOBSBAWM, Eric y RANGER, Terence (Eds.) La invención de la tradición, Barcelona: Crítica.

LÓPEZ MONROY, José de Jesús, 2000, Notas para el estudio del derecho indiano. En: Anuario mexicano de historia del derecho. México D.F., n. 11-12, p. 86.

MENESES, María Paula, 2004, Toward interlegality? Traditional healers and the law in the postcolonial Mozambique. En: Oficina do CES. Coimbra, n. 202.

MERRY, Sally Engle, 2004, Una clasificación de la justicia popular. En: El otro derecho. Bogotá. n. 30 .

MONTAIGNE, Michel de. De los caníbales. Disponible en: < http://bibliotecaignoria.blogspot. com/2010/02/michel-de-montaigne-de-los-canibales.html > . Acceso en: 17/11/2011.

PAREDES MARTÍNEZ, Carlos, 2003, Instituciones coloniales en poblaciones tarascas. Introducción, adaptación y funciones. En: PAREDES MARTÍNEZ, Carlos y TERÁN Marta (Coords.). Autoridad y gobierno indígena en Michoacán. v. I. México: COLMICH/ CIESAS/ INAH/ UMSNH.

ROULAND, Norbert, 2003, Nos confins do direito. São Paulo: Martins Fontes.

SANTOS, Boaventura de Sousa, 2007, Para além do Pensamento Abissal: Das linhas globais a uma ecologia de saberes. En: Revista Crítica de Ciências Sociais. Coimbra, n. 78.

SHAKESPEARE, William, 2009, Macbeth-El mercader de Venecia- Las alegres comadres de WindsorJulio César-La tempestad. México: Porrua.

VARELA, Roberto, 1984, Expansión de sistemas y relaciones de poder. Antropología política del estado de Morelos. México D.F.: UAM.

ZÁRATE HERNÁNDEZ, José Eduardo, 2001, Los señores de utopía. Zamora: COLMICH /CIESAS. 